\title{
ENSINO DE COMUNICAÇÕES NO CURSO DE GRADUAÇÃO EM ENFERMAGEM DA ESCOLA DE ENFERMAGEM DA UNIVERSWADE FEDERAL DE MINAS GERAIS
}

\author{
Lélia Marı Madeira* \\ Selme Silquetra Matos** \\ Zidia Rocha Magalhäes***
}

Mapzira, L M.et al. Enaido de comunicaça no Curbo de Graduaqua em Enfermagem da Escola de Enfermagem da Universidade Federal de Minas Gera1s. Rev. Esc. Enf. USP, v. 28 , n. 2, p. 199-214, ago. 1994.

Consıderando a importância da comunicaçāo em todas as açōes de enfermagem procurou-se verificar como se dá o pracesso ensino-aprendizagem deste tema no curso de graduação da Escola de Enfermagem da Universidade Federal de Minas Gerais. Os dados foram coletados através de entrevistas realizadas com ciocentes e discentes do referido curso. Os resultados revelaram que o problema básico desse processo nāo é "o que" ensinar mas "como" ensinar o conteudo sobre comunucação.

UNITERMOS: Ensino de comunicaçāo; comunicação em enfermagem.

\section{INTRODUÇĀO}

A comunicação é uma atividade de importância vital, muito ampla e que tem sido alvo de vários estudiosos.

Nas áreas de saúde e educação as especialidades da comunicação tem sido estudadas numa busca contínua de subsidiar os profissionais para melhor desempenho de suas funçōes.

$\mathrm{Na}$ enfermagem, a comunicação é um dos instrumentos básicos da profissão, junto à observação, destreza manual, criatividade, aplicação de princípios científicos, método científico, planejamento, trabalho em equipe e avaliação, de acordo com FERRAZ A. F. et al. (1988).

Como instrumento básico da profissão a comunicação deve permear o fazer do enfermeiro. Já na década de 60, HORTA (1979) enfatiza a necessidade de habilidades de comunicaçāo do enfermeiro para a execução do

\footnotetext{
- Doutoranda em Enfermagem da EEUSP, Mestre em Enfermagem Pediátrica; Professora adjunto da EEUFMG

- Mestranda em Enfermagem da EEUFMG. Professora assistente da EEUFMG

... Mestre em Enfermagem, Professora assistente da EEUFMG
} 
processo de enfermagem, principalmente para a coleta de dados do histórico de enfermagem.

Para STEFANELLI (1993), "comunicação é denominador comum de todas as ações de enfermagem e influi, decisivamente, na qualidade da assistência prestada àquele que necessita dos cuidados profissionais dos enfermeiros". A autora também afirma que a comunicação, de forma explícita ou implícita, é um dos componentes das teorias de enfermagem que norteiam a assistência STEFANNELI (1990).

Por ser a comunicação uma atividade tão básica e indispensável ao desempenho das funçōes do enfermeiro, é que deve ser, não só ensinada mas também avaliada durante o processo de formação. ABBATT; MCMAHON (1988) consideram as habilidades de comunicação essenciais na prestação de cuidados de saúde e afirmam que, ao se planejar o ensino de qualquer atividade para o profissional de saúde, deve-se considerar e incluir no planejamento as habilidades de comunicação que serão necessárias ao desempenho daquela atividade.

HARRISON et al (1989), falando sobre os modelos de comunicação terapêtica e de competência interpessoal recomendam que a enfermeira aprenda a desempenhar certas habilidades básicas de comunicaçāo e dizem que os dois modelos oferecem guias quanto às habilidades que deveriam ser ensinadas na educação em comunicação e usadas para avaliar a efetividade de programas específicos de ensino.

KASSCH (1984), em seu trabalho sobre competência interpessoal e comunicação na assistência, comenta: por ser o relacionamento enfermeirapaciente o principal agente de mudança terapêutica e a comunicação o meio pelo qual o relacionamento se estabelece, a competência em comunicação é uma função que depende da habilidade de quem assiste para que se possa manter esse relacionamento.

FERRAZ A. E. P. et al. (1988) repensando a influência do avanço tecnológico na comunicação, relata que apesar deste avanço, na prática tem-se observado dificuldades de comunicação enfermeiro/equipe de enfermagem em todo o processo de comunicação.

Conhecedores das deficièncias e dificuldades na formação do enfermeiro temos presenciado, cotidianamente, situaçōes que nos levam a questionar sobre o que, como e quando o estudante de enfermagem está aprendendo sobre o processo de comunicação.

Mais uma vez, STEFANELLI (1993) referindo-se à importância da comunicação em enfermagem e à necessidade do ensino da mesma, reforça as assertivas dos outros autores dizendo que "... a enfermeira tem de conhecer como se dá o processo de comunicação e todos os elementos a ele pertinentes, como utilizá-lo na sua prática para que o paciente a considere um elemento de ajuda, um outro ser humano, capaz e eficiente, com que ele pode interagir, partilhar suas idéias, seus anseios, seu sofrimento e necessidade de ajuda". Portanto, a enfermeira tem que adquirir sua "competência interpessoal" através da aquisição de uma base teórica sobre comunicação geral e comunicação interpessoal para que possa aplicar as teorias ao seu cotidiano profissional. 
Sabemos também que comunicação em enfermagem é "algo" muito amplo e que, ao mesmo tempo, possui muitas especificidades. Por exemplo, comunicar-se efetivamente é importante em qualquer situação, no entanto precisa-se conhecer as especificidades para se comunicar com uma gestante, com uma màe, com a criança em diferentes faixas etárias, com a pessoa sadia ou com alguém com ou em algum estado mórbido, e assim por diante.

Sobre o ensino de comunicação no curso de graduação em enfermagem temos o trabalho de FERRAZ A. F. et al. (1988) quando pesquisaram o ensino dos instrumentos básicos de enfermagem nas Escolas de Enfermagens da grande São Paulo. As autoras coletaram dados de discentes e docentes e verificaram que a comunicaçāo foi destacada pelos dois segmentos, como um dos instrumentos básicos mais importantes para a profissão.

Este resultado é corroborado por STEFANELLI (1993) quando diz que “apesar da comunicação ser reconhecida, preconizada e, às vezes, utilizada como instrumento básico de enfermagem, o seu estado ainda está para ser aprofundado de modo a ser mais bem conhecido e utilizado pelas enfermeiras em sua prática diária na comunicação com seus pares, membros da equipe de saúde, supervisores, clientes, famílias, comunidade, entre outros."

No que concerne às especificidades, cada autor, dentro de sua área de atuaçāo, enfoca o processo de comunicação relacionando-o às características do sujeito/interlocutor, seja numa situação individual ou coletiva. Como exemplo, podemos citar: WHALEY; WONG (1987), que tratam da comunicação enfermagem/pais/criança, dentre outros.

CARVALHO et al (1988), em seu estudo sobre o ensino de comunicação nas Escolas de Enfermagem do Brasil, encontraram que o tema comunicação é abordado em 22 disciplinas, unidades ou tópicos dos vários currículos dos cursos de enfermagem. As disciplinas Enfermagem Psiquiátrica e Administração são as mais citadas na abordagem ao assunto. Este trabalho identificou, também, várias dificuldades existentes no ensino de comunicaçāo em enfermagem, entre elas, o desconhecimento das teorias por parte dos docentes e a incoerência entre o ensino e prática. Finalmente, seus resultados sugerem maior atenção ao ensino deste assunto, tanto em carga horária quanto no que diz respeito ao referencial teórico, estratégias e recursos didáticos.

Preocupa-nos, portanto, quais conteúdos estão sendo ensinados e quais estão sendo apreendidos pelo graduandos de enfermagem. Esta preocupaçào se justifica não só pela relevância do conteúdo mas, também pela necessidade de se adequar o curriculo às reais necessidades do futuro enfermeiro.

Neste sentido, propusemos o presente estudo com os seguintes objetivos:

1. Verificar a percepção de docentes e discentes da Escola de Enfermagem da Universidade Federal de Minas Gerais (EEUFMG), sobre a comunicação em enfermagem.

2. Verificar como ocorre o processo ensino-aprendizagem sobre comunicação, no curso de graduação da EEUFMG. 


\section{Metodologia}

O presente estudo é do tipo exploratório descritivo e foi realizado na Escola de Enfermagem da UFMG, em Belo Horizonte, no periodo de setembro a novembro de 1992 .

A população estudada constituiu-se de:

- 11 docentes de 9 disciplinas do ciclo profissional do curso de graduação em enfermagem que mencionaram ensinar comunicação em seus programas (anexo I).

- 14 discentes de semestres subseqüentes àquelas disciplinas que mencionaram ter ensinado comunicação. Desse modo, foram entrevistados 3 alunos do $5^{\circ}$ e do $7^{\circ}$ periodo, 5 alunos do $8^{\circ}$ periodo, e 3 recem-formados.

A coleta de dados foi realizada pelas próprias pesquisadoras utilizandose um roteiro de entrevista semi-estruturada (anexo II e III), aplicáveis a docentes e discentes, respectivamente.

Inicialmente, foram contatados todos os coordenadores de disciplinas do ciclo profissional, afim de detectarmos em quais disciplinas se ensinava comunicação.

Posteriormente, foram contatados os docentes responsaveis pelos referidos conteudos para a realizaçāo da entrevista.

Logo após as entrevistas com os docentes, os discentes de periodos subsequentes foram contatados, esclarecidos sobre os objetivos da pesquisa e convidados a participar da mesma. Solicitamos a participação de, no máximo, 3 alunos por periodo. No entanto, 5 alunos do $8^{\circ}$ periodo pediram-nos para serem entrevistados, dai a divergência entre o numero de alunos do $8^{\circ}$ e os demais penodos.

\section{Apresentação e análise dos dados}

Numa tentativa de conhecer todo o processo ensino-aprendizagem sobre comunicação em enfermagem coletamos dados de docentes e discentes os quais passamos a apresentar, procurando analisá-las através de uma leitura qualitativa.

Das 18 disciplinas do ciclo profissional do curso de enfermagem da EE.UFMG, 9 mencionaram ministrar conteúdo sobre comunicação em seus programas (anexo I). E, destas 9, foram entrevistados os docentes indicados pelos coordenadores respectivos, por serem os responsáveis pelo conteúdo ministrado. Em 2 disciplinas foram entrevistados 2 professores, perfazendo um total de 11 entrevistas docentes.

\section{a) Dados dos docentes}

Inicialmente, pretendiamos conhecer o que pensam os docentes sobre a comunicaçāo em enfermagem. Nas respostas à esta pergunta encontramos, expressōes tais como: 
Importantissima;

Imprescindível;

Básica;

Procedimento importante;

Essência da assistência de enfermagem;

Instrumento básico da enfermagem;

Intrinseca à atividade de enfermagem;

Base do sucesso de uma intervenção terapêutica.

Justificando estas qualificação os entrevistados se expressaram da seguinte maneira sobre a comunicação em enfermagem:

Representa uma etapa da relação enfermeiro-paciente;

Promove a comunicação interprofissional, com o cliente e a familia;

Envolve os aspectos do processo de trabalho em enfermagem;

Habilidade que permite a atuaçäo do enfermeiro junto ao paciente:

Permite o estabelecimento da confiança no profissional.

Ao analisarmos as expressōes utilizadas pelas respondentes podemos inferir que, de modo geral, todas tem um significado comum para a comunicação em enfermagem que poderíamos traduzir de uma forma simplificada por "A comunicação é uma atividade essencial na prestação da assistência de enfermagem porque possibilita a interação cliente/profissional".

Esta assertiva é corroborada por diversos autores que falam sobre comunicação e profissionais da saúde/enfermagem. ABBATT; MCMHOM (1988), destacam a comunicação como habilidade imprescindivel para o desempenho de atividades do profissional da saude. junto às habilidades manuais e de tomada de decisóes e aos fatores capacitantes que são o conhecimento e atitude necessárias. FERRAZ A. E. P. et al. (1988), elaboraram seu próprio conceito de instrumentos básicos da enfermagem, dentre os quais inclui a comunicação. Para elas "instrumentos básicos são o conjunto de atitudes, habilidades e conhecimentos que fundamentam a formação e o exercicio profissional do enfermeiro, fornecendo os subsidios essenciais à prestaçāo da assistência, ao ensino e à pesquisa".

Frente à importância da comunicaçāo para o exercício da enfermagem consideramos que todos os respondentes lhe conferem o valor merecido.

Ao questionarmos sobre que conteúdos sobre comunicação são abordados em suas disciplinas obtivemos dos docentes uma lista dos mesmos. Decidimos agrupá-los segundo a ordem crescente das disciplinas no curriculo, a fim de facilitar a compreensão, das mesmas.

Conteúdos ministrados:

Conceito geral de comunicação;

Comunicação como instrumento básico da enfermagem;

Importância da comunicaçāo para aplicação dos demais instrumentos da enfermagem;

Fatores e barreiras que interferem na comunicação geral;

Tipos de comunicaçāo verbal e não-verbal;

Importância dos tipos de comunicação no contexto assistencial; 
Estratégias de comunicação terapêutica e formas não terapêuticas de comunicação;

Facetas da comunicação com equipe, paciente e familia;

Especificidades da comunicação com paciente oncológico;

Conteúdos de comunicação relacionados aos problemas do paciente neurológico;

Avaliação das habilidades (capacidade de comunicação do paciente neurológico e formas de interaçāo com ele);

Comunicação terapêutica com pacientes em crise;

Barreiras de comunicação que o paciente neurológico enfrenta para se reintegrar à comunidade;

Educaçāo para a saúde;

Comunicação terapêutica;

Comunidade entre a mão e a criança;

Resgate dos princípios básicos de comunicaçāo;

Modelos de comunicação uni e bidirecional;

Visão geral sobre processo de comunicação;

Comunicação efetiva com a mãe e a criança;

Relacionamento profissional com o cliente, mãe ou criança;

Importância da comunicação em enfermagem pediátrica:

Técnica de comunicação com a mulher;

Comunicação do recém-nascido;

Comunicaçāo administrativa;

Instrumentos administrativos de enfermagem;

Metodologia de comunicar-se naturalmente.

Pela descrição dos conteúdos percebe-se que o assunto é abordado de forma ampla enfocando os aspectos básicos da comunicação e as especificidades dependendo das características do cliente/interlocutor, ou seja, considerando-se o contexto e os sujeitos envolvidos no processo de comunicaçāo.

Os conteúdos englobam as especificidades da comunicação com o feto: com a criança; o adulto, enfatizando a mulher, passando por situaçōes caracterizadas como patológicas e/ou de crise. Englobam ainda o ensino de comunicação em situaçōes de administração e de educação em enfermagem.

Verificamos que o conteúdo é ministrado obedecendo-se uma certa lógica indo do geral ao específico, porém, com algumas situaçōes repetitivas, sem a preocupação do resgate do que foi aprendido anteriormente.

Consultados sobre "Como o conteúdo de comunicação é ministrado em sala de aula?", os docentes informaram, principalmente, sobre carga horária destinada ao assunto e as estratégias de ensino utilizadas.

Quanto à carga horária as disciplinas: Fundamentos de Enfermagem $4^{\circ}$ periodo, Enfermagem Psiquiátrica $-6^{\circ}$ periodo, Enfermagem Pediátrica e Enfermagem Obstetrícia $-7^{\circ}$ periodo e Administração Aplicada à Enfermagem $-8^{\circ}$ periodo, explicitam-na em seus programas, oscilando entre $2 \mathrm{e}$ 20 horas/aula. As demais disciplinas, apesar de considerarem a importância do assunto e ministrá-lo, não destinam carga horária especifica para o mesmo. 
Quanto às estratégias de ensino utilizadas, foram citadas:

Preleçāo/aula expositiva, com ou sem uso de transparência;

Visitas à unidade de internação para aplicação de técnicas de comunicaçäo terapêutica;

Discussão em grupo;

Leitura de textos;

Elaboraçāo de folhetos educativos;

Dramatização;

Simulação através de videoteipe;

Oficina de massa e utilizaçāo de figuras;

Técnicas de apresentação de pessoas através de grupos;

Exercícios após aula expositiva;

Técnicas de relaxamento;

Leitura orientada;

Laboratório;

Pós-teste.

Esta listagem de estratégias para o ensino teórico de comunicaçāo contempla as orientaçōes de ABBATT; MCMAHON (1988), que afirmam ser a comunicação muito mais que apenas falar. Envolve ouvir, perguntar, explicar, persuadir e, por isso, é imprescindível a utilização de métodos de ensino que permitem praticar as habilidades em comunicação. Os metodos de ensino sugeridos pelos autores são: discussão em grupo, dramatização, experièncias de campo/entrevistas e exercícios escritos.

No entanto, observamos o predominio do uso de aula expositiva apesar de estar sempre associada à outra estratégia ou recurso audiovisual. Foram mencionadas estratégias, tais como: "exercício", "laboratório", "pós-teste" sem a explicitação da forma como são implementados em sala de aula.

Estas constataçōes nos levam a refletir sobre a capacitação didático-pedagógica do professor de $3^{\circ}$ grau. Questionamos o entendimento dos docentes sobre processo ensino-aprendizagem e estratégias/técnicas/métodos de ensino e avaliação. Esta preocupação procede face à resposta obtida de uma docente: "Não tem estratégia para o ensino de comunicação. Eu utilizo leitura orientada, discussāo em sala de aula e pós-teste".

Analisando as respostas sobre o conteúdo mencionado, a carga horária destinada e as estratégias utilizadas vemos que existe uma incoerência entre estas, uma vez que a carga horária não nos parece compatível com a amplitude do conteúdo e com as características das estratégias de ensino utilizadas.

O ensino em campo de prática ocorre de forma muito diversa da sala de aula, a partír da relação professor/aluno que na teoria, em geral, é de $1 / 40$ e na prática varia de $1 / 5$ até $1 / 10$. Isto significa que, muitas vezes, apenas um professor trata do assunto em sala de aula e os demais irão tratá-la, cada um a seu modo, com suas próprias concepçōes, no campo de prática. Neste sentido, um docente afirma que: "...procuro enfocar a comunicaçāo terapêutica mas, percebo que há diferença no enfoque de outros professores em relação à valorização da comunicação como um todo e, em especial, da comunicação terapêutica". 
A comunicação no campo de prática é ensinada ou reforçada de diversas formas como destacamos das falas dos entrevistados:

A disciplina trabalha com o processo de enfermagem e a comunicação surge logo na coleta de dados para o histórico de enfermagem, quando os alunos tem que registrar todas as informações verbais e não verbais do paciente, tanto no hospital quanto no ambulatório;

Discussões a partir das dificuldades que os alunos encontram para saber: como, quando e o que falar com o paciente e familiares; como lidar com a morte, a dor; formas de comunicar com outros membros da equipe: médicos, auxiliares, técnicos;

Interação dos alunos com os pacientes - observaçāo e discussāo sobre as necessidades dos pacientes e as atitudes dos alunos. Não é um processo sistematizado nem destacado e, nem sempre, o professor consegue trabalhar com todos os alunos as dificuldades em relaçào à comunicação aluno/pacien. te; de;

Elaboraçăo de folhetos educativos à partir da necessidade da comunida-

Discussāo, estudo de caso, relacionamento individual e grupal;

Realização da consulta de enfermagem à criança;

Orientaçāo aos familiares;

Reuniōes dos alunos com grupos de mäes para aplicação dos conhecimentos sobre comunicaçāo;

Realização do clube de mães;

Alunas aplicam técnicas de apresentação e fazem oficina de massa em grupo no treinamento de pessoal de enfermagem;

Vivência do próprio aluno ao relacionar-se consigo mesmo e, consequen. temente, com o cliente;

Aplicação dos conhecimentos de comunicação durante o estágio no alojamento conjunto;

Orientação de gestantes e puérperas pelo aluno;

Discussão do conteúdo teórico, chamando atenção para sua aplicaçāo prática;

Vivência dos problemas relacionados à administração da assistência de enfermagem, registros, comunicação formal e informal;

Vivência dos problemas técnico-administrativos;

$O$ ensino na prática ocorre informalmente; chamo a atenção do aluno sobre formas de comunicaçāo individual ou em grupo, durante reuniōes com màes, em palestras nas escolas, etc;

Identificação de dificuldade de comunicação durante o planejamento de atividades: correção, sugestōes, etc.

Pelo relato dos professores percebe-se que o ensino de comunicação em enfermagem na prática sofre uma solução de continuidade pois, são poucas as disciplinas cujos docentes tem conhecimento do que foi tratado em sala de aula e que procuram resgatar esse conhecimento e aplicá-lo na prática. Por isso, acreditamos que, apesar desses docentes se orientarem pelo planejamento da disciplina, as diferenças ocorrem devido às diferentes concepçōes teóri- 
co-metodológicas e pedagógicas e pela diversidade de experiências vivenciadas pelos docentes e devido à diversidade de oportunidades que são oferecidas aos estudantes.

ABBATT; MACMAHON (1988) dizem que a prática é essencial no ensino de habilidades de comunicação e que o estudante precisa treiná-la em diferentes situaçōes. Também reforçam a necessidade do ensino se dar de forma continuada procurando-se sempre resgatar o conhecimento anterior do aluno à medida que outros forem sendo acrescidos, segundo sua complexidade e/ou especificidade.

Para conhecermos todo o processo ensino-aprendizagem sobre comunicaçào em enfermagem perguntamos aos docentes como é avaliado a aprendizagem desse conteúdo. Apenas 5 disciplinas afirmam realizar avaliação somativa, com finalidade de dar nota ao conteúdo aprendido pelo estudante, seja através de questōes em prova escrita ou de observaçào no campo de prática. Outros mencionaram avaliaçāo formativa, em geral, através da observação e posterior discussão com o aluno do campo de prática.

Mais uma vez, nos deparamos com a diversidade de estratégias de avaliação da aprendizagem e, o que é mais sério, com a nảo avaliação. Alguns professores responderam:

Não existe avalią̧āo especifica para este conteuido...,

Ocorre de forma indireta...;

Não è destacado; está integrado à avaliaçāo da disciplina;

Avaliaçāo da comunidade sobre o conteudo dos folhetos educativos:

Não existe mecanismo direto e explicito;

Não existe avaliação formal... não é possivel avaliar como conteúdo de sala de aula.

ABBATT; MACMAHON (1988) afirmam que por ser a habilidade de comunicaçāo tão importante é que ela deve ser avaliada. Porém, deve-se avaliar o estudante dentro do contexto mais próximo possivel daquele em que irá desempenhar suas atividades profissionais. Assim, os exames convencionais, como: questōes descritivas, múltipla-escolha, provavelmente, nāo irá precisar no futuro. Para uma avaliação válida e confiável os autores sugerem: a observação de estudante no campo de prática porém, com a utilização de uma "check-list" ou escala de valores ou avaliação da comunicação escrita e verbal do estudante. A comunicação verbal pode ser avaliada atraves de situações simuladas. No entanto, eles destacam que o mais importante é que se avalie aquelas habilidades de comunicação que, realmente, serão utilizadas pelo estudante como profissional.

Frente aos dados obtidos dos professores, verificamos que o assunto comunicação em enfermagem está sendo ensinado no ciclo profissional da EEUFMG, no entanto, são poucos os professores envolvidos com o conteúdo teórico, levando a diferentes enfoques e valorização na prática.

Outra constatação è que o assunto é ministrado seguindo a ordem do geral para o especifico porém, não vislumbramos preocupação dos docentes em resgatar e/ou reforçar conhecimentos anteriores. 


\section{b) Dados dos discentes}

Para a apresentação dos resultados das entrevistas com os discentes decidimos agrupá-los por períodos e apresentá-los seguindo a ordem de aparecimento no currículo para facilitar a análise dos mesmos.

Sobre o que pensam a respeito da comunicação e enfermagem os entrevistados responderam assim:

$5^{\circ}$ periodo

$\hat{E}$ muito importante...permite a interaçāo entre a enfermagem, o paciente e a equipe multiprofissional.

$7^{\circ}$ periodo

Fundamental;

São formas de conversar entre os profissionais e o paciente;

Facilita o atendimento ao paciente;

$8^{\circ}$ período

Essencial; extremamente importante; impossivel fazer enfermagem sem comunicação;

Recém-formados

É através da comunicação que se estabelece os objetivos do trabalho... é o meio de se chegar a determinado proposito.

De modo geral, percebe-se que os alunos valorizam a comunicação para o processo de trabalho em enfermagem, relacionando-a sempre ao seu objeto de trabalho que é o paciente.

Ao serem perguntados sobre o que aprenderam sobre comunicação até o momento, no curso de graduação, os alunos listaram os assuntos dos quais se lembravam. Vale ressaltar que "comunicação terapêutica e não terapèutica" foi mencionada por alunos do $5^{\circ}, 7^{\circ}$ e $8^{\circ}$ periodos, porém não foi mencionado pelos recém-formados.

Este fato nos preocupa se considerarmos que a comunicaçāo terapêutica é essencial à prática profissional e, como afirma STEFANELLI (1993) as estratégias de comunicação terapêutica devem ser aprendidas por todas as enfermeiras que desejam prestar assistência de modo holístico, ou seja, que atenda às dimensões física, psíquica, cultural, espiritual, social e intelectual do paciente.

Alunos do $7^{\circ}$ período afirmaram ter aprendido "educação para a saude", explicando que foi através de "como dar aula para a comunidade".

Os alunos do $8^{\circ}$ periodo explicitaram o que haviam aprendido da seguinte forma:

Comunicação terapèutica que é executar mais que falar, saber ouvir, respeitar sentimentos das pessoas...;

Noçōes de relacionamento inter e intra-equipe;

Comunicação com o cliente;

Como abordar diferentes pacientes;

Várias formas de comunicar na enfermagem utilizando diferentes lin. guagens e todos os sentidos.

As respostas de recém-formados despertaram a nossa atenção: 
"Durante o curso em geral a gente não dá a importância que deve aos assuntos, só depois que a gente sente a falta e vai procurar saber... me lembro do assunto em Pediatria, Psicologia, Fundamentos, Administração..."

Por esta fala é possível captar a superficialidade das lembranças que a ex-aluna possui sobre o assunto, mencionando inclusive disciplina cujo o professor informou não abordar comunicação em seu programa.

- "Não considero ter aprendido pois näo estava consciente da importân. cia da comunicação para o trabalho do enfermeiro e, por isso, não sistematizei o conteúdo passado pelas disciplinas."

Esta fala corrobora a anterior indicando que, durante a formação do enfermeiro, nảo estamos conseguindo ensinar comunicação de forma que o aluno aprenda este conteúdo relacionado-o à sua realidade profissional.

Preocupados com as habilidades de comunicação que os estudantes estavam adquirindo durante sua formação HARRISON et al. (1989) iniciam seu estuda questionando: "apesar dos estudantes poderem aprender habilidades de comunicaçāo, não se sabe se eles retém estas habilidades, se as incorporam aos padrōes de comportamento nas interaçōes com o cliente ou se continuam a melhorar a efetividade na comunicaçāo à medida que adquirem mais conhecimento e experiência". Ao final da pesquisa os autores verificaram que, a medida que o aluno avança em conhecimento e experiència, eles se sentem menos capaz de atuar terapeuticamente. Assim, indagam: "os estudantes de enfermagem simplesmente esquecem as importantes habilidades terapêuticas ou estāo adotando estratégias mais pragmáticas para lidar com as contingências interpessoais e com o stress do ambiente de trabalho?"

A seguir, foi perguntada aos alunos se estavam aplicando os conhecimentos sobre comunicação adquiridos e em que situação.

Apenas aquele que afirmou não ter aprendido disse, logicamente, nảo estar aplicando.

Treze responderam estar aplicando os conhecimentos, em situações, tais como:

$5^{\circ}$ periodo

Diálogo com pacientes e amigos;

Convivio com paciente e colegas;

Contato diário com pacientes, colegas e equipe multiprofissional:

$7^{\circ}$ periodo

No trabalho, em casa, na associação de bairros e na igreja;

Com pessoas doentes, outros profissionais e com professores;

Com pacientes e familiares;

$8^{\circ}$ período

Durante a consulta de enfermagem com a mãe e a criança;

Com os pacientes, as pessoas aplicando a comunicação terapèutica;

Relacionamento com colegas, professores, clientes e equipe multi-profissional; na elaboração de folhetos explicativos para pacientes;

Relacionamentos com pacientes e familiares;

Recém-formados

Relacionamentos com a equipe; 
Relacionamento com a mãe, com a criança, funcionários e médicos, anotaçōes (registro) nos prontuários;

Relacionamentos com o cliente e com alunos (atividade docente);

Conversando com coordenadores de enfermagem $e$ chefias do hospital (administração); elaboração de relatórios.

Mais uma vez, constatamos que a aplicação de conhecimentos sobre comunicação tem como principal alvo as relaçōes aluno e ou profissional/cliente. Verificamos ainda que outros interlocutores foram sendo mencionados segundo o periodo em que se encontrava o aluno, obedecendo a ordem de complexidade e as especificidades da disciplina ou das atividades profissionais exercidas pelo entrevistado, no momento.

Ressaltamos, o fato de que as relações com colega, funcionários ou equipe multi-profissional foi mencionado por respondentes em todos os níveis o que é muito bom, considerando ser a enfermagem uma profissāo que se caracteriza pelo trabalho em equipe. Lamentavelmente, a comunicação escrita, indispensavel na enfermagem, só foi citada por recém-formados.

Retornando aos resultados obtidos dos docentes consideramos que o conteúdo sobre comunicação que é ministrado no curso de graduação é abrangente e seria suficiente para formação do enfermeiro.

Como relatado pelos professores também o ensino deste conteúdo na prática é muito rico, ocorrendo através de uma gama enorme de experièncias de aprendizagem em diversas situaçōes da prática profissional.

No entanto, se tomarmos as informaçōes oferecidas pelos alunos e recém-formados verificamos que muito pouco deste conteúdo foi apreendido. principalmente se considerarmos as situações em que os mesmos estão aplicando os conhecimentos adquiridos.

Ao nosso ver, esta situaçāo reflete as deficièncias no ensino deste conteúdo que ficaram transparentes nas informaçōes dos docentes, demonstrando haver incongruências entre tempo destinado e estratégias de ensino e avaliação utilizadas.

Os alunos também não demonstraram ter assimilado a importância sobre comunicação em enfermagem que foi mencionado tanto pelos professores quanto por eles mesmos.

Esta constatação nos remete ao estudo do SONOBE (1990), realizado com alunos de graduação que indicam, em que outros resultados, “.... necessidade de uma mudança no ensino da comunicação em enfermagem, sugerindo: desenvolvimento de trabalhos de comunicaçāo entre alunos e professores antes de entrarem em ambiente hospitalar, comunicação ministrada como uma disciplina em todos os semestres; treinando prático anterior aos estágios; incentivo após a formaçāo, na prática hospitalar, do processo de comunicaçāo com paciente."

\section{Conclusão}

O estudo nos indica sérias incoerências no ensino de comunicação em enfermagem no ciclo profissional do curso de graduação em enfermagem da Escola de Enfermagem da Universidade Federal de Minas Gerais. 
A deficiência no ensino de comunicaçāo propriamente dito tem seu início na própria orientação curricular que não realça as características e/ou qualidades de comunicador inerentes ao profissional enfermeiro. Conseqüentemente, as disciplinas, em seus programas, nāo destacam a importancia do assunto.

Os professores que ministram o conteúdo de comunicação em enfermagem, apesar de considerá-lo básico, fundamental e imprescindivel na formaçāo do enfermeiro nảo obtém êxito deste conhecimento na medida em que os alunos não conseguem explicitar ou explicitam muito pouco sobre o que aprenderam de comunicação.

Os resultados apontaram dificuldades e deficiências no processo ensino-aprendizagem como um todo, relacionadas tanto à capacitação pedagógica do docente quanto à infra-estrutura na qual este está ensinando. Assim, fica evidente que o problema básico relacionado ao ensino de comunicação no Curso de Graduação em Enfermagem não é "o que" ensinar, mas "como" ensinar 0 assunto.

MADEIRA. L. M. et al. Communication teaching in the undergraduate nursing course from the Nursing School at Universidade Federal de Minas Gerais. Rev. Esc. Enf. USP, v.28, n.2. p. 199-214, aug. 1994

Facing the importance of the communication in all nursing activities, in this paper the authors try to verify how has been occurring the teaching-learning process related to the communication subject during the undergraduate nursing course in the Nursing School at Federal University of Minas Gerais. The data were colected by intervewing professors aud students from the undergraduate course. The results showed that the basic problem in this process is not "what" to teach but "how" to teach the subject.

UNITERMS: Communication teaching; Communication in nursing.

\section{REFERÊNCLAS BIBLIOGRÁFICAS}

1. ABBATT, F.: MCMAHON, R. Teaching health-care workers: a practical guide. London. Macmillan. 1988.

2. CARVALHO. E.C et al. O ensino de comunicação nas Escolas de Enfermagem no Brasıl. In: SIMPOSIO BRASILEIRO DE COMUNICAÇĀO EM ENFERMAGEM. 1, Riberrào Preto. 1988. Anais. Ribeirào Preto. EERP-USP. 1988.

3. FERRAZ. A.E.P. et al. O processo de comunicaçao em enfermagem: visảo do aluno de graduaçào. In: SIMPOSIO BRASILEIRO DE COMUNICAÇĀO EM ENFERMAGEM. 1, Ribeirào Preto. 1988. Anais. Ribeirão Preto. EERP.USP. 1988. p. 182-6

4. FERRAZ. A.F. et al. Instrumentos básicos: aspectos relacionados ao processo ensino-aprendizagem no curso de graduação de escolas de enfermagem da grande São Paulo. Rev.Esc.Enf.USP ., v 22, p.161-88, 1988. Número especial.

5. HARRISON. T.M. et al. Assessing nurses communication: a cross-sectional study. West.J.Nurs.Res. , v.11, n.1, p. 75-91, 1989. 
6. HORTA, W. de A. Processo de enfermagem. Sảo Paulo, EPU, 1979.

7. KASCH, C.R. Interpersonal competence and communication in the delivery of nursing care. ANS.Adv.Nurs.Sci ., v.6, n.2. p. 71-90, 1984.

8. STEFANELLI, M.C. Comunicaçāo enfermeira-paciente: teoria, ensino e pesquisa. Sào Paulo, 1990. 139p. Tese(Livre-Docência)- Escola de Enfermagem, Universidde de São Paulo.

9. Comunicação com o paciente-teoria e ensino. Sảo Paulo. Robe. 1993.

10.SONOBE. H.M. Comunicação aluno-paciente: questỏes e obstáculos. In: SIMPÓSIO BRASILEIRO DE COMUNICAÇĀO EM ENFERMAGEM, 2, Ribeirảo Preto, 1990. Anais, Ribeirão Preto, EE.RP.USP, 1990. p.552-65.

11.WHALEY, L.F.; WONG, D.L. Enfermagem pediátrica. 2.ed. Rio de Janeiro, Koogan, 1987. cap. 2, p.58-67: A comunicaçāo e a entrevista em saúde. 


\section{Anexo I}

Ensino de Comunicaçāo no Ciclo Profisaional do Curso de Enfermagem da EE.UFMG

\begin{tabular}{|c|c|c|c|}
\hline \multirow[b]{2}{*}{ Periodo } & \multirow[b]{2}{*}{ Disciplina } & \multicolumn{2}{|c|}{ Ensina } \\
\hline & & Sim & Nào \\
\hline $1^{\circ}$ & Introdução ao Estudo da Enfermagem & & $x$ \\
\hline $4^{\circ}$ & Fundamentos Enfermagem & $x$ & \\
\hline $4^{\circ}$. & $\begin{array}{l}\text { Introducāo a Metodalogia Cientifica aplicada a } \\
\text { enfermagem }\end{array}$ & $\mathbf{x}$ & \\
\hline $4^{\circ}$ & $\begin{array}{l}\text { Introduçāo a Metodologia da Pesquisa Aplicada a } \\
\text { Enfermagem }\end{array}$ & & $x$ \\
\hline $4^{\circ}$ & Introduçáo à Saúde Priblica & & $x$ \\
\hline $4^{\circ}$ & Enfermagem em Primeiros Socorros & & $x$ \\
\hline $5^{\circ}$ & Enfermagem Médica-Cirügica I & & $x$ \\
\hline $5^{\circ}$ & Psicologia aplicada a Enfermagem & & $x$ \\
\hline $6^{\circ}$ & Enfermagem em Doencas Transmissiveis & & $x$ \\
\hline $6^{\circ}$ & Didática aplicada à Enfermagern & $x$ & \\
\hline $6^{\circ}$ & Enfermagem à Neurologia & $\mathrm{x}$ & \\
\hline $6^{\circ}$ & Enfermagem em Oncologia & $\mathrm{x}$ & \\
\hline $6^{\circ}$ & Enfermagem Psiquiatrica & $\mathbf{x}$ & \\
\hline$\tau$ & Enfermagem Pediátrica & $x$ & \\
\hline 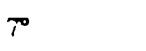 & Enfermagem Obstétrica e Neonatal I & $x$ & \\
\hline $8^{\circ}$ & Enfermagem de Saúde Pública I & $\mathbf{x}$ & \\
\hline $8^{\circ}$ & Administraçāo aplicada à Enfermagem & $\mathbf{x}$ & \\
\hline
\end{tabular}




\section{Anexo II}

\section{ROTEIRO DE ENTREVISTA-DOCENTE}

Nome da Disciplina:

Periodo:

Carga Horária: Teórica: Prática: Total:

1. O que vocè pensa sobre a comunicaçāo em Enfermagem?

2. No ensino de sua disciplina que conteúdo sobre comunicaçāo é abordado?

3. Como é ministrado este conteúdo em sala de aula?

- Estratégia de ensino (forma e recursos)

- Tempo destinado

4. Como ocorre o ensino deste conteúdo no campo de pratica de sua disciplina?

5. Como é avaliado a aprendizagem deste conteúdo em sua disciplina?

OBS.: Solicitar plano de aula se possivel.

\section{Anexo III}

\section{ROTEIRO DE ENTREVISTA-DISCENTE}

Nome:

Periodo:

1. O que vocè pensa sobre Comunicação em Enfermagem?

2. O que você aprendeu sobre Comunicação no Curso de Enfermagem até o momento?

3. Vocè está aplicando os conhecimentos adquiridos?

Se negativo, justifique.

Se positivo, em que situação? 